97 DELETION OF TACI PROTECTS AGAINST AUTOIMMUNE DISEASE IN LUPUS-PRONE MOUSE MODELS WITH DIFFERENT DISEASE MECHANISMS

${ }^{1}$ EX Lim*, 'W Figgett, ${ }^{1} \mathrm{~F}$ Mackay, ${ }^{2} \mathrm{M}$ Hibbs. ${ }^{1}$ Peter Doherty Institute- The University of Melbourne, Department of Immunology, Melbourne, Australia; ${ }^{2}$ Monash University, Department of Immunology and Pathology, Melbourne, Australia

\subsection{6/lupus-2017-000215.97}

Background and aims Systemic lupus erythematosus (SLE) is a debilitating autoimmune disease driven by production of autoantibodies which targets various organs including the kidney. SLE is notoriously heterogeneous, arising from numerous possible mechanisms and there is no current efficient treatment. Many of these distinct mechanisms can be reproduced in different mouse models of SLE. Excess production of the B cell activating factor of the TNF family (BAFF) has been previously implicated as a disease-associated factor in a subset of SLE patients, particularly by signalling through transmembrane activator and cyclophilin ligand interactor (TACI) to drive pro-inflammatory autoantibody production. We investigated if deletion of TACI in various mouse models of SLE would be protective.

Methods Flow cytometry was used to characterise B cell and antibody-producing plasma cell subsets in these mouse models. Autoantibody detection and serum cytokine levels were measured using ELISA whilst kidney histopathology was assessed using paraffin-embedded kidney sections.

Results Indeed, the results show that deletion of TACI in BAFF-transgenic mice and other mouse models with separate disease mechanisms, prevented disease by restricting autoantibody production and decreased kidney pathology. Loss of TACI protected these mice from disease whilst maintaining B cell numbers.

Conclusions These data provide increased support for choosing TACI as a key target for therapeutic intervention, which may be applicable in treating multiple subtypes of SLE. This would offer treatment efficacy without the serious adverse events linked with extensive loss of B cells.

\section{TERIFLUNOMIDE SODIUM CAN EFFECTIVELY CONTROL PROGRESS OF SPONTANEOUS LUPUS OF MRL/LPR MOUSE}

C Ma, B Qiu, L He, L Bao, L Sun, L Zhang, N Liu, J Luo, F Xiao*. Cinkate Pharmaceutical Intermediates Co.-Ltd., development centre, shanghai, China

\subsection{6/lupus-2017-000215.98}

Background and aims Teriflunomide sodium (CK8) is the sodium salt of the metabolites of the leflunomide. Leflunomide has been approved for the treatment of lupus nephritis by CFDA.The aim of the study was to evaluate the therapeutic effect of CK8 on the course of disease in SLE-prone MRL/lpr mice, compared with leflunomide and glucocorticoid. Methods Ten to eleven-weeks-old female mice displaying clinical symptoms of SLE were given CK8 $(20 \mathrm{mg} / \mathrm{kg}, 30 \mathrm{mg} / \mathrm{kg}$, $40 \mathrm{mg} / \mathrm{kg}$ ) gavage once a day for 8 weeks. Control mice received gavage of leflunomide $(30 \mathrm{mg} / \mathrm{kg})$, Prednisone Acetate $(2 \mathrm{mg} / \mathrm{kg})$ or vehicle. Survival, proteinuria, lupus like skin lesion, lymphoid organ, level of anti-dsDNA antibodies and IL-17 in serum, double negative(DN) $\mathrm{T}$ cells and regulatory $\mathrm{T}$ cell were analysed.

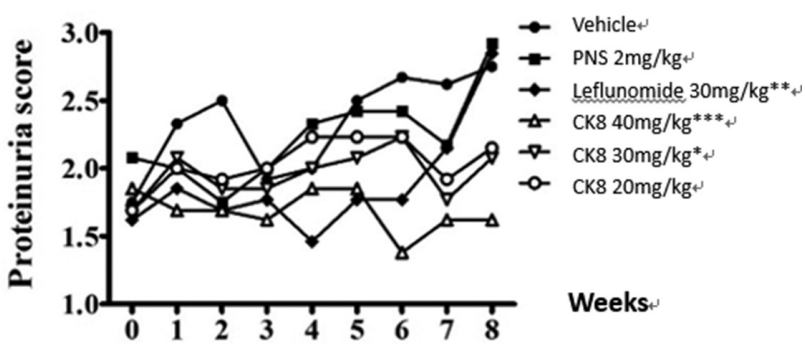

Abstract 98 Figure 1

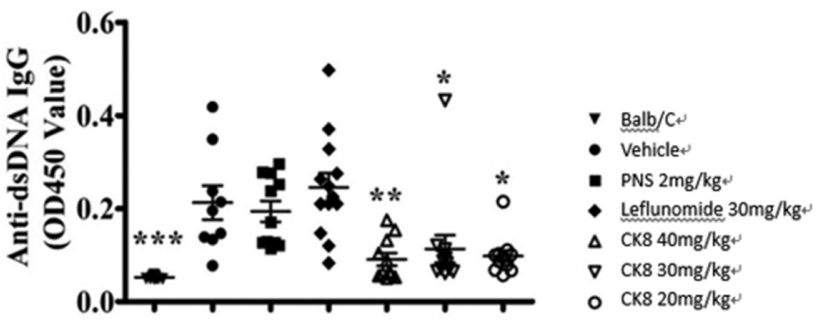

Abstract 98 Figure 2

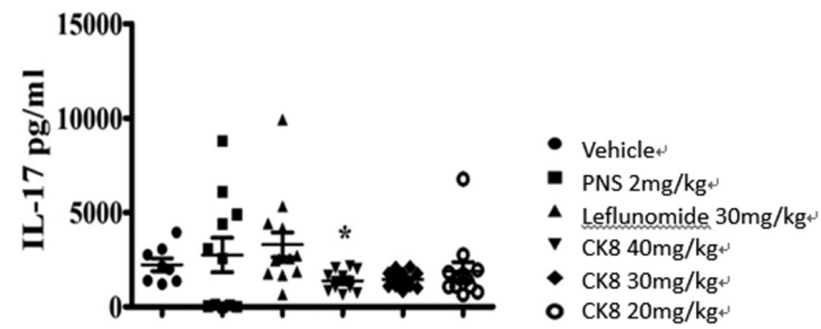

Abstract 98 Figure 3

Results The results show that after treatment 8 weeks , 3 of 12 mice in vehicle control group led to death because of severe SLE, but mice all survived in CK8 $30 \mathrm{mg} / \mathrm{kg}$ group. CK8 can effectively improve the skin lesions, swollen of lymph nodes and spleen and other symptoms of lupus, reduce proteinuria (figure 1), the level of serum anti-dsDNA antibody (figure 2) and IL-17(figure 3), and a significant dose-response relationship. Further study found that treatment with CK8 can significantly reduce glomerular nephritis and interstitial nephritis lesions in MRL/lpr mouse ,but leflunomide without obvious improvement . CK8 can significantly decrease proportion of the DN T cells, increase proportion of regulatory $\mathrm{T}$ cells.

Conclusions The results suggest that the CK8 can effectively control progress of spontaneous lupus of MRL/lpr mouse, improve the symptoms and signs.

\section{HYPER-ACTIVATION AND IN SITU RECRUITMENT OF INFLAMMATORY V $\delta 2$ T CELLS CONTRIBUTES TO DISEASE PATHOGENESIS IN SYSTEMIC LUPUS ERYTHEMATOSUS}

W Mo*, S Yin, X Zhang. Beijing peking union medical college hospital, rheumatology, Beijing, China

10.1136/lupus-2017-000215.99 